\title{
Geotechnical Aspects of Weak Sandstone from Recife/Brazil
}

\author{
O.M. Oliveira, R. Bim, G.B. Nunes, R.A.R. Higashi
}

\begin{abstract}
Diagenetic processes acting on the sandy sediments of the marine plains from the city of Recife/Brazil formed different types of sandstones. Two blocks of the sandstone formed in the Pleistocene epoch were collected to perform characterization tests and determine their mechanical properties. This sandstone is present in a depth between 0.3 and $4.5 \mathrm{~m}$ and with a thickness between 0.5 and $4.5 \mathrm{~m}$. The average values obtained for their specific dry weight and porosity are respectively equal $16.5 \mathrm{kN} / \mathrm{m}^{3}$ and $30 \%$. In the unconfined compressive strength tests were obtained mean values of resistance and deformability module respectively, equal to $2 \mathrm{MPa}$ and $162 \mathrm{MPa}$, classifying this sandstone as weak rock. An isotropic behavior was observed when performing direct shear tests in the direction parallel and perpendicular to the level of the terrain. The sandstone block collected at a greater depth presented higher resistance parameters in these tests with cohesion of $393 \mathrm{kPa}$ and a friction angle of $55.6^{\circ}$. A case study is presented where the geological and geotechnical characteristics of these sandstones were explored as support for a building foundation, and a good performance was observed.
\end{abstract}

Keywords: marine plain, weak rock, weak sandstone.

\section{Introduction}

The two marine transgressions occurring within the Pleistocene and Holocene Epoch of the Quaternary Period, formed in the Metropolitan Region of the city of Recife/Brazil, a marine terrace with distinct geological characteristics. The sandy deposits of these terraces were submitted to diagenetic processes that allowed the formation of sandstones with different cementing agents.

It is of fundamental importance to understand the role of marine transgressions in the formation of these marine terraces, due to the great amount of sediments brought to the continent and its peculiar form of deposition. The advancement of the sea by the receding coastline (transgression) occurs due to fluctuations of its relative level, as a result of complex interactions between the surface of the ocean and the continent. Deglaciations and changes in the volume of ocean basins due to plate tectonics and the local level changes of the continent are factors of change in these relative positions (Suguio et al., 1985). Marine transgression breaks the dynamic balance of coastal regions due to its high energy in the wave front, causing sediment erosion, deposition in deeper regions and lower transport energy. During the process of marine regression, the erosive process is reversed. The wave front erodes the sediments deposited during the transgressive process with transport and deposition of the same to the post-beach. In the regressive phase, the formation of beach ridges occurs - which together form the plain of marine sediments.
The transformations imposed by natural elements, such as marine transgressions, rivers, mangroves and man, resulted in the formation of several geological units in the metropolitan region of the city of Recife, with very different geotechnical properties. The units deposited in the Quaternary Period are Pleistocene, Undifferentiated and Holocene marine terraces, alluvial and mangrove deposits.

The sandstones studied here are present in the marine terrace formed in the penultimate transgression occurring 120.000 years ago, display an altimetric level varying between 7 and $11 \mathrm{~m}$, and a small slope on the coastline. The sediments deposited during the regression of the sea are formed by quartz grains with dimensions ranging from fine to coarse sand, incoherent in surface and of white color. With increasing depth, these sediments are consolidated by a cementing agent that gives it a brown coloration. These weak sandstones are present in practically all the extension of this marine terrace in the form of a slab, located near the surface that has been little explored as a foundation support in the construction of buildings. This type of sandstone is a common occurrence in the coastal plains of the coastal region of Brazil. The lack of knowledge of its geological and geotechnical properties leads engineers to design deep foundations for the buildings, which are common practice in the metropolitan area of the city of Recife. When used for surface foundation purposes in buildings, its deformability and strength parameters are framed within conservative models (Gusmão Filho, 1998). This article has as main ob-

Orlando Martini de Oliveira, D.Sc., Associate Professor, Departamento de Engenharia Civil, Universidade Federal de Santa Catarina, Florianópolis, SC, Brazil. e-mail: oliveiraorlando@hotmail.com.

Rodrigo Bim, Ph.D. Student, Universidade Federal de Santa Catarina, Florianópolis, SC, Brazil. e-mail: fale_com_ro@yahoo.com.br.

Gabriel Bellina Nunes, Ph.D. Student, Universidade Federal de Santa Catarina, Florianópolis, SC, Brazil. e-mail: gabrielbnunes@gmail.com.

Rafael Augusto dos Reis Higashi, D.Sc., Associate Professor, Departamento de Engenharia Civil, Universidade Federal de Santa Catarina, Florianópolis, SC, Brazil. e-mail: rrhigashi@gmail.com.

Submitted on August 24, 2017; Final Acceptance on February 21, 2018; Discussion open until August 31, 2018.

DOI: $10.28927 /$ SR.411061 
jective to demonstrate that these weak sandstones could be adequate as a support for shallow foundations.

During the characterization studies of these sandstones, their physical properties were obtained, in addition to their coefficient of permeability and aspects related to texture and structure. Its resistance parameters were determined in direct shear tests and uniaxial compression tests. For the determination of its area of occurrence, depth and thickness, the database of drilling of the geotechnical chart of the city of Recife was used.

\section{Materials and Methods}

\subsection{Determination of the occurrence area of sandstones}

The Geotechnical Chart of the Metropolitan Region of Recife was prepared in 1990 based on geotechnical drilling data, among other types of results. From this database, the drillings of the coastal region were selected, where two marine plains are inserted and were constructed by process of variations of the relative sea level occurring in the Holocene and Pleistocene epochs. The results of the analyses of
41 drillings indicated that the weak sandstones are present only in the marine plain formed during the Pleistocene Epoch, denominated in the geotechnical chart as Quaternary Pleistocene Unit (QP). These sandstones were identified in 22 drillings. The other 19 drillings, where the presence of the sandstone was not found, were concentrated in the Holocene Marine Terrace $(\mathrm{QH})$ and in the Pleistocene Marine Terrace, whose sediments of marine origin were reworked by the river action being denominated as Quaternary Undifferentiated Unit (QU). The region of study with identification of the drilling sites is shown in Fig. 1. The drillings where the presence of the sandstone was identified are presented in this figure by circles. Beside these circles, the depth of the surface of this sandstone followed by its thickness are indicated in parentheses. The points indicated by triangle correspond to drillings where these sandstones were not found. The weak sandstones present in the QP unit are found in depths ranging from 0.3 to $4.5 \mathrm{~m}$, with a thickness between 0.5 and $4.5 \mathrm{~m}$.

Two geological profiles were determined using the survey data. The A-A' profile, shown in Fig. 2, is substan-

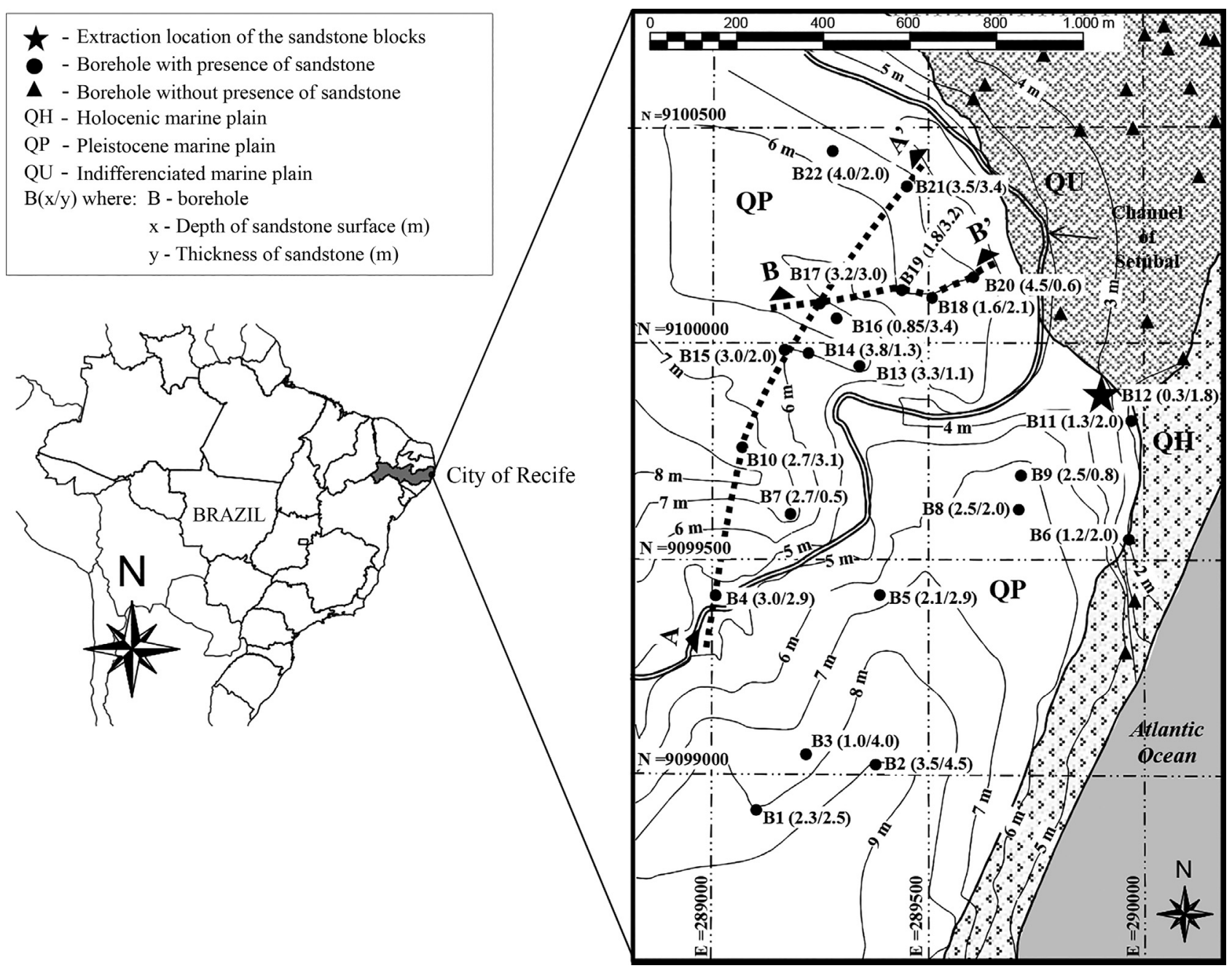

Figure 1 - Location of the drillings in the geotechnical chart of the city of Recife/Brazil. 


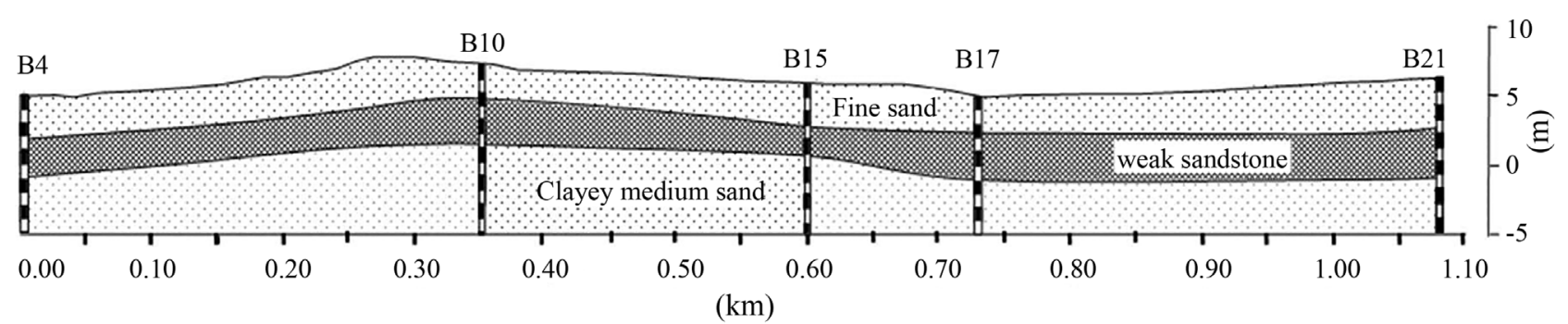

Figure 2 - Geological profile A-A'.

tially parallel to the coastline. This profile was plotted with the use of boreholes B4, B10, B15, B17 and B21. The profile B-B' represents a different direction being shown in Fig. 3. In this figure, a reduction in the thickness of the sandstone can be observed as it approaches the boundary of its marine terrace in the borehole B20. Figures 2 and 3 demonstrate that these sandstones are present in the shape of a stone slab. This spatial arrangement and proximity to the ground surface are what gives these sandstones great potential as support material for buildings having shallow foundations.

\subsection{Sampling procedures}

The removal of weak sandstone samples for performing laboratory tests involves some difficulties. When found during engineering projects, they are often avoided due to lack of knowledge of their geotechnical behavior (Dobereiner, 1984). The extraction of samples with rotary probe presents great difficulty due to the mechanical stresses transmitted and the circulation of water that causes the disaggregation of this weak rock (Kanji, 2014). The solution for the removal of blocks presents another difficulty, related to the difficulties of finding a place without buildings, given that it is a densely populated region, where this sandstone is not so deep and is above the level of the water table. The equipment generally used for the removal of soil blocks is not appropriate for working on weak rocks. The results presented here were obtained from 2 cubic blocks, with $0.3 \mathrm{~m}$ side, removed from the same excavation. In order to verify possible variations of physical and mechanical properties, the blocks were removed from different depths. Block 1 represents the depth of 0.3 to $0.6 \mathrm{~m}$ and block 2 rep-

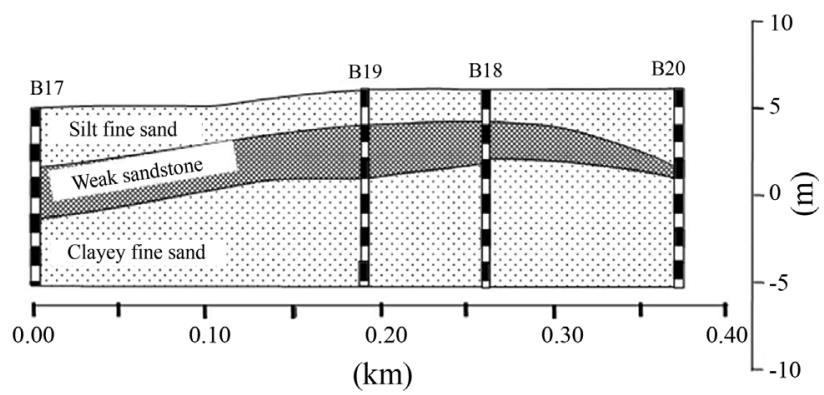

Figure 3 - Geological profile B-B'. resents the depth of 0.7 to $1.0 \mathrm{~m}$. Figure 4 shows the place of the executed excavation for removal of weak sandstone blocks. The lack of local experience, as these are the first blocks removed from this rock formation, leads to improvisation in the use of available equipment such as hoe, shovel, pick, mallet, slitter and saw. Initially, a cube block with a $0.4 \mathrm{~m}$ edge was molded with the aim to avoid any disturbance caused by the impact of the tool (Fig. 4a). The finishing work, with a reduction of the length of the edge of the block to $0.3 \mathrm{~m}$, was executed with the use of mallet and slicer (Fig. 4b). The process of removing only 1 block required a time of $5 \mathrm{~h}$, and the labor of 3 workers. The 2 blocks were removed from the upper sandstone region, and they were representative of the settlement place of the buildings surface foundations.

The profile presented in Fig. 5, obtained from two boreholes executed at the removal site of blocks 1 and 2, indicates that the soil is composed of a small layer of fine and medium sand, of around $0.2 \mathrm{~m}$, with presence of organic matter, passing to unconsolidated white sand with an average thickness of $0.5 \mathrm{~m}$, followed by a transition to the brown sandstone, which presents a thickness ranging from 1.5 to $2 \mathrm{~m}$. The level of the water table, located at a depth of $1.8 \mathrm{~m}$, presents the same coloration of the sandstone and characteristic smell of organic matter. The Nspt values, indicated in Fig. 5, correspond to the number of blows given for the nailing of the last $0.3 \mathrm{~m}$ of the standard sampler. The blows are given by a standard hammer with $65 \mathrm{~kg}$ with a free fall height of $0.75 \mathrm{~m}$ (ABNT, 2001). The region of Fig. 5, defined as sandstone, shows Nspt higher than 40 which characterizes it, according to ABNT (2001), as a very compact sediment. The layer of clayey sand, located just below the sandstone, is classified as a compact to soft sediment. The values of the Nspt only begin to increase from the depth of $14 \mathrm{~m}$ where the sediments are from compact to very compact.

The execution of works where there is a need to excavate these sandstones are also problematic. In another place, belonging to the same marine terrace, located $3 \mathrm{~km}$ from the location where the 2 blocks were removed, great difficulty was found in the excavation of a drainage channel. The lack of research and local knowledge have led to serious implementation difficulties, resulting in excavation machines breaking down due to excessive efforts. 

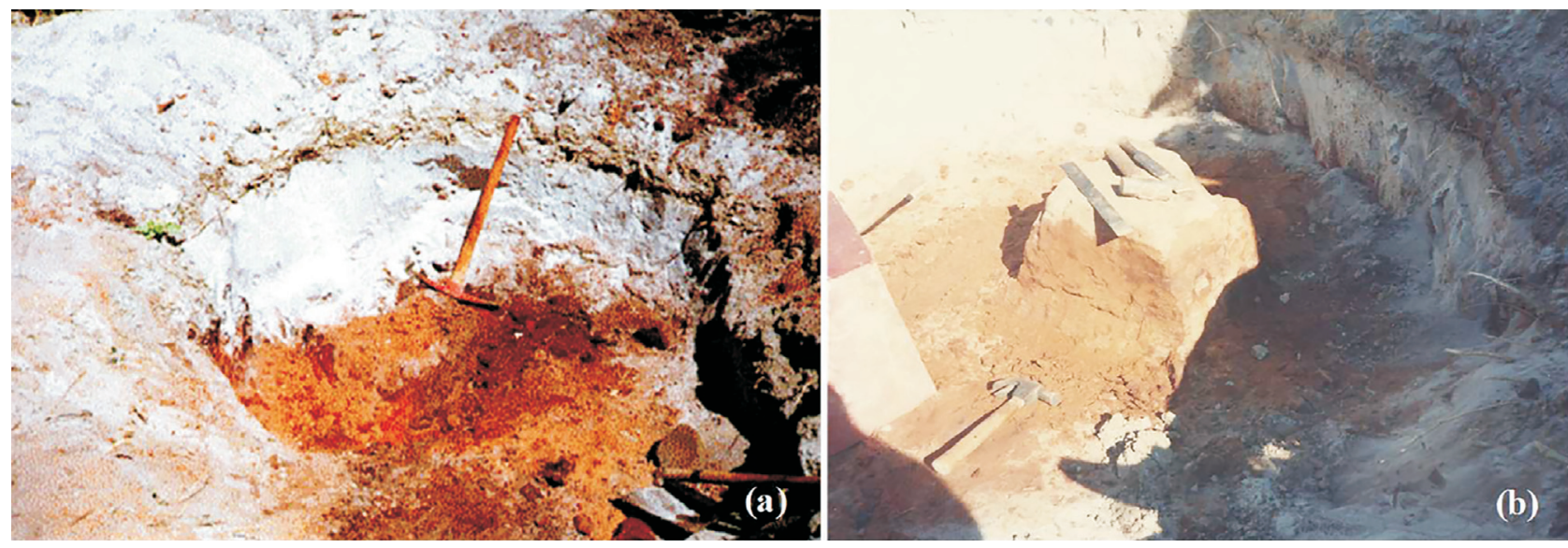

Figure 4 - Place of the executed excavation for removal of weak sandstone blocks.

\subsection{Geotechnical characterization}

For the determination of the physical indices, 10 specimens of each block were molded with cylindrical shape on a manual lathe. The volume was obtained with a pachymeter using for this the average of 4 determinations of height and diameter. The determination of the natural moisture contents (ABNT, 2016a), porosity and the density of the solid particles (ABNT, 2016b) allowed the definition of the physical properties that are presented in Table 1. The values of these parameters are indicated by their range and the average value placed in parentheses.

The physical properties of blocks 1 and 2 are practically the same, being indicative of their homogeneity. In relation to block 1 , it can be observed that the sandstone sample from block 2 shows a darker brown tonality. During work visits to superficial foundations executed on this sandstone, it can be observed that the sandstones present two shades of brown. The workers involved in the excavation project claim that the region of the sandstone that has a darker shade of brown is more difficult to excavate. To verify this aspect tests were carried out to determine the organic material content using the method of burning

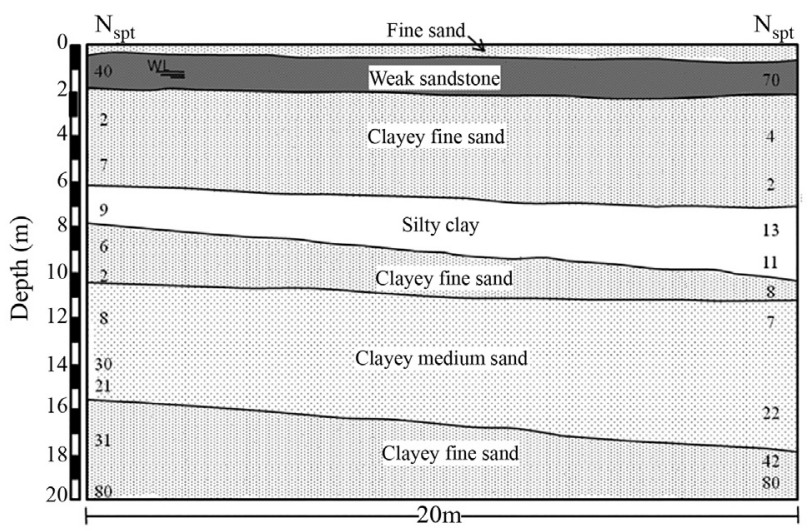

Figure 5 - Geological profile of the place where the soft sandstone blocks were removed.
(ABNT, 1996). In these tests it was verified that the darker sandstones present organic material content of $3.9 \%$ and in the sandstones with a lighter tonality this value is $3.5 \%$. This is probably one of the factors that justifies the greater resistance to excavation presented by the darker sandstone. The presence of organic material is associated with humus which is composed of fulvic acids, humina and humic acid, considered as one of the cementing agents of these sandstones (Assis, 1990). In order to obtain the samples for grain size analysis, the sandstones were moistened since in these conditions they are more easily disaggregated. Due to the weak cementation of the sandstones, their disaggregation occurs with translation of the grains, possibly resulting in the breaking of more intemperate grains. However, it is assumed that this breakage occurs in a limited way without altering the results. Dobereiner (1984) found that grain breakage occurs in sandstones with resistance greater than $20 \mathrm{MPa}$, thus extrapolating the limit of weak rocks. The grain size analyses (ABNT, 2016c), presented in Fig. 6, were determined for the sand layer located above the sandstone, and for the sandstones of blocks 1 and 2. It can be observed that the three particle size analyses represent a poorly selected sediment with great predominance of the sandy fraction. The percentages by weight of each type of sediment, obtained from Fig. 6, are presented in Table 2. There is a great similarity between the grain size analyses

Table 1 - Results of characterization tests of the sandstone blocks 1 and 2.

\begin{tabular}{lccccc}
\hline Block & $\begin{array}{c}\text { Depth } \\
(\mathrm{m})\end{array}$ & $\begin{array}{c}\gamma_{s} \\
\left(\mathrm{kN} / \mathrm{m}^{3}\right)\end{array}$ & $\begin{array}{c}\gamma_{d} \\
\left(\mathrm{kN} / \mathrm{m}^{3}\right)\end{array}$ & $\begin{array}{c}\mathrm{W}_{\text {ant. }} \\
(\%)\end{array}$ & $\begin{array}{c}\mathrm{n} \\
(\%)\end{array}$ \\
\hline 1 & $0.3-0.6$ & 26.0 & $\begin{array}{c}15.6-17.4 \\
(16.4)\end{array}$ & $\begin{array}{c}9.1-11.8 \\
(9.8)\end{array}$ & $\begin{array}{c}33-40 \\
(37)\end{array}$ \\
2 & $0.7-1.0$ & 26.0 & $\begin{array}{c}15.5-17.2 \\
(16.6)\end{array}$ & $\begin{array}{c}8.5-13.3 \\
(10.4)\end{array}$ & $\begin{array}{c}34-41.5 \\
(37)\end{array}$ \\
\hline
\end{tabular}

$\gamma_{s}$ - density of the solid particles; $\gamma_{d}$ - specific dry weight; $\mathrm{w}_{\text {nat }}$ - natural moisture content; $\mathrm{n}$ - porosity. 


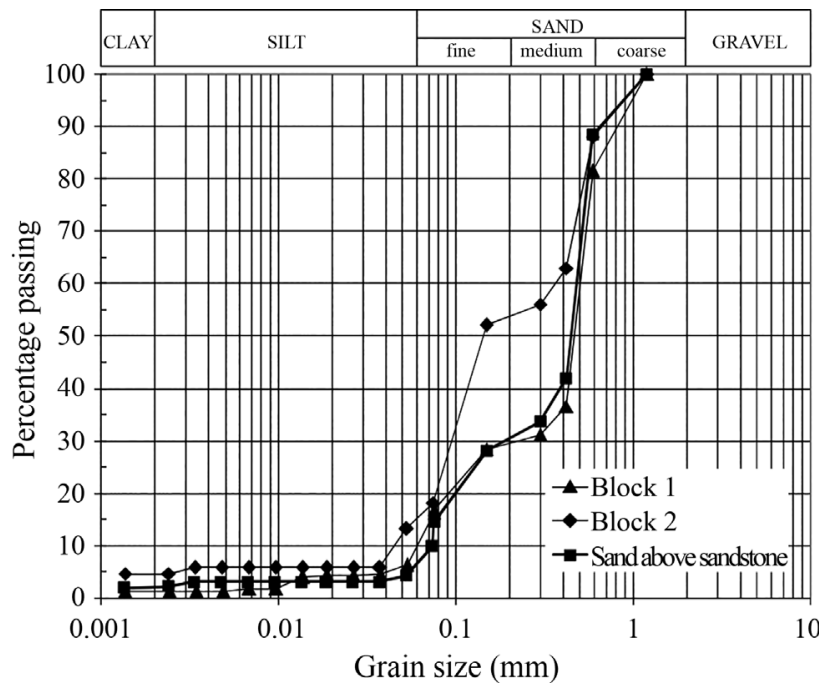

Figure 6 - Grain size distribution of sand and sandstone of blocks 1 and 2 .

of the sand and the sandstone of block 1 which are closer to the surface of the terrain. However, it is shown in Table 2 that there is a reduction in the amount of medium sand and increase in the amount of fine sand and silt as the depth increases. In this way it is verified that in block 1 there is predominance of medium sand and in block 2 a predominance of fine sand.

\section{Results and Discussion}

\subsection{Aspects related to composition, texture and cemen- tation}

The aspects related to the composition and texture of these sandstones and determination of the probable type of cementation were investigated through scanning electron microscopy images JEOL JSM-6390LV. Figure 7 shows some of the images obtained with enlargements between 50 and 1000 times. These images demonstrate that the grains of medium sand are wrapped in a matrix of fine sand. The grains of medium sand are not in contact with each other which implies a mechanical behavior commanded by fine sand (Figs. 7a and 7b). The presence of bioclasts (shell and algae) were not observed, indicating that these were probably dissolved by the action of humic acid present in solution in the groundwater. The sandy sediments are poorly selected, presenting angular to sub-angular shape and have low sphericity (Fig. 7c).
In the image with enlargement of 1000 times, shown in Fig. 6, the presence of a thin film is observed, which surrounds the grains of medium and fine sand, that probably corresponds to the cementing agent (Fig. 7d).

The analysis of X-rays emitted by the sample bombarded with a fine electron beam allows to quantify the chemical elements present in its constitution. The chemical elements present in the film covering the sand particles and their percentage by weight obtained from two different points of the sample are presented in Table 3. The large amount of carbon shown in Table 3 is an indicator of the presence of products derived from the decomposition of organic matter, such as humic acid. Energy dispersive spectroscopies (EDS) of these two points of analysis are shown in Fig. 8.

The diagenetic processes that formed the sandstones present in the Pleistocene Marine Terrace require more detailed investigations to identify its type of cementation. The cementation of these sandstones has been cited by some researchers as resulting from the precipitation of iron and the presence of humic acid. The action of humic acid as a cementing agent has been studied by several researchers and its ability to form aggregations of soil particles has been recognized (Baver, 1968; Tisdall \& Oades, 1982). Research carried out by Andrade \& Dominguez (2002), in the soft sandstones of the Caravelas region, located in the state of Bahia, concluded that iron oxide and humic acid are the cementing agents. Manso et al. (2003) reached the same conclusion when studying the sandstones of Ipojuca, located in the state of Pernambuco/Brazil. The sandstones investigated by these researchers are present on Pleistocene Marine Terrace.

During the formation of the marine terrace of the city of Recife, resulting from the oscillations of the middle sea level, lagoons were formed that later became brackish marshes, whose plant species contributed to the enrichment of the soil in organic matter (Suguio et al., 1985).

The humic acids resulting from the decomposition of organic matter, are very aggressive and capable of reducing iron oxides making them more soluble and transporting them in solution over long distances by lateral movement of groundwater (Bigarella et al., 2007). The iron oxides back to precipitate by oxidation reactions, where deposition occurs on the water level oscillation region, providing a brown coloration to the soil (Bigarella et al., 2007).

From the previously mentioned aspects it is very probable that the Pleistocene sandstones studied here pres-

Table 2 - Granulometric fractions of sand and sandstone of blocks 1 and 2.

\begin{tabular}{lcccccc}
\hline Material & Depth $(\mathrm{m})$ & Clay $(\%)$ & Silt $(\%)$ & Fine sand $(\%)$ & Medium sand $(\%)$ & Coarse sand $(\%)$ \\
\hline Sand & $0-0.3$ & 2.4 & 4 & 30 & 52 & 11.6 \\
Block1 & $0.3-0.6$ & 1.2 & 8.2 & 29.4 & 42.7 & 18.5 \\
Block2 & $0.7-1.0$ & 4.3 & 12.2 & 53.5 & 18 & 12 \\
\hline
\end{tabular}



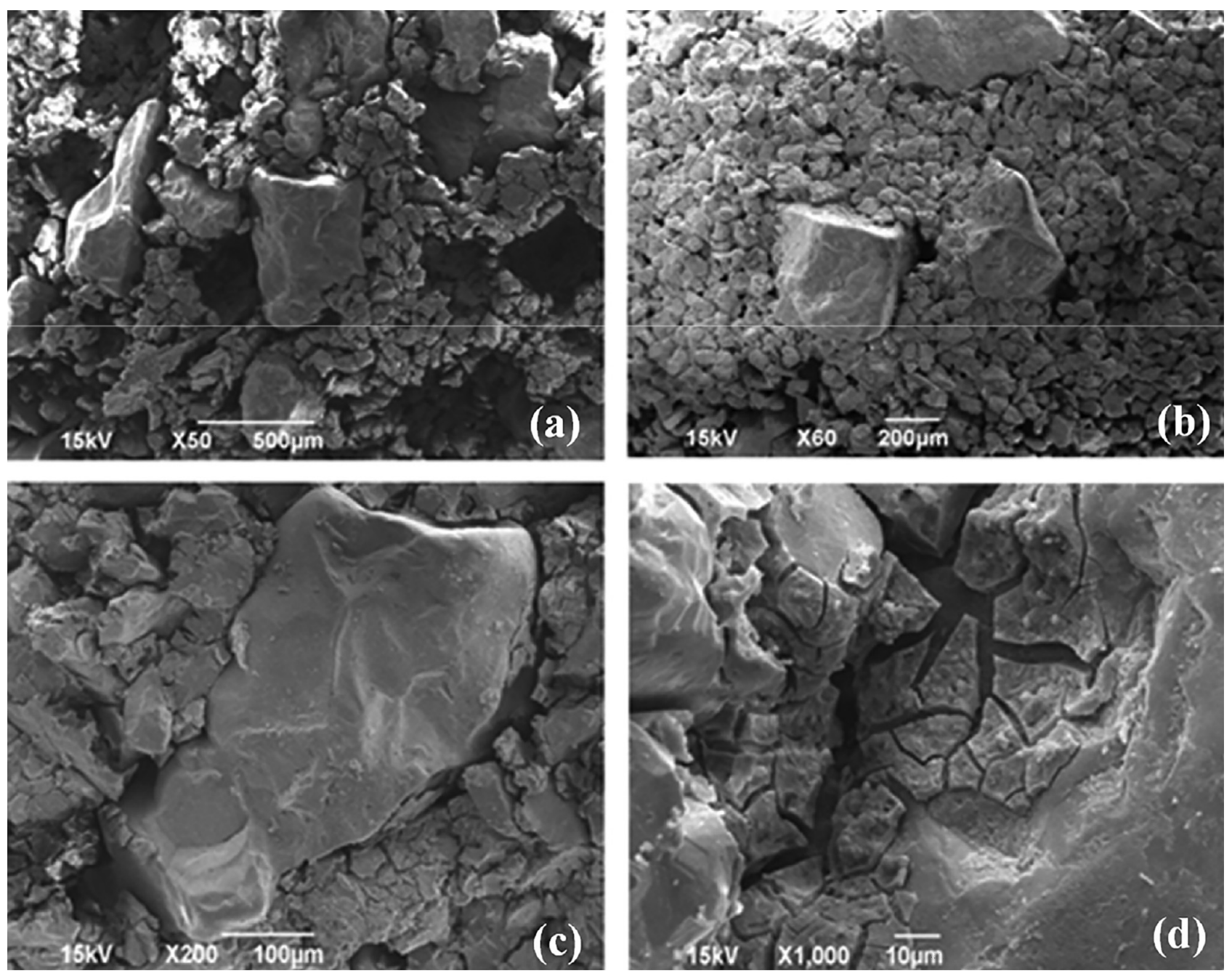

Figure 7 - Scanning electron microscopy images of the sandstone.

ent a cementation by iron oxide and by humic acid. However, the iron oxide plays a predominant role in the mechanical resistance of these sandstones. The iron source is probably associated with the sediments of the Barreira Group, represented by cliffs bordering the marine plain where these sandstones are found. Mabesoone (1967) affirms that the Barreira Group is the main source of iron that cemented the beach sediments of the coastal strip from the city of Recife - located in the state of Pernambuco - to the city of João Pessoa, -located in the state of Paraíba. Following this line of reasoning, these ferruginous solutions originated from the Barreira Group, migrated laterally in solution inside the sandy sediments of the Pleistocene Terrace,

Table 3 - Percentage by weight of the chemical elements present in the cementation of the sandstone.

\begin{tabular}{lcccccc}
\hline Point & C-K & N-K & O-K & Al-K & Si-K & Tc-L \\
\hline 1 & 32.53 & 30.87 & 15.51 & 5.56 & 8.98 & 6.55 \\
2 & 48.25 & - & 13.06 & 3.63 & 35.06 & - \\
\hline
\end{tabular}
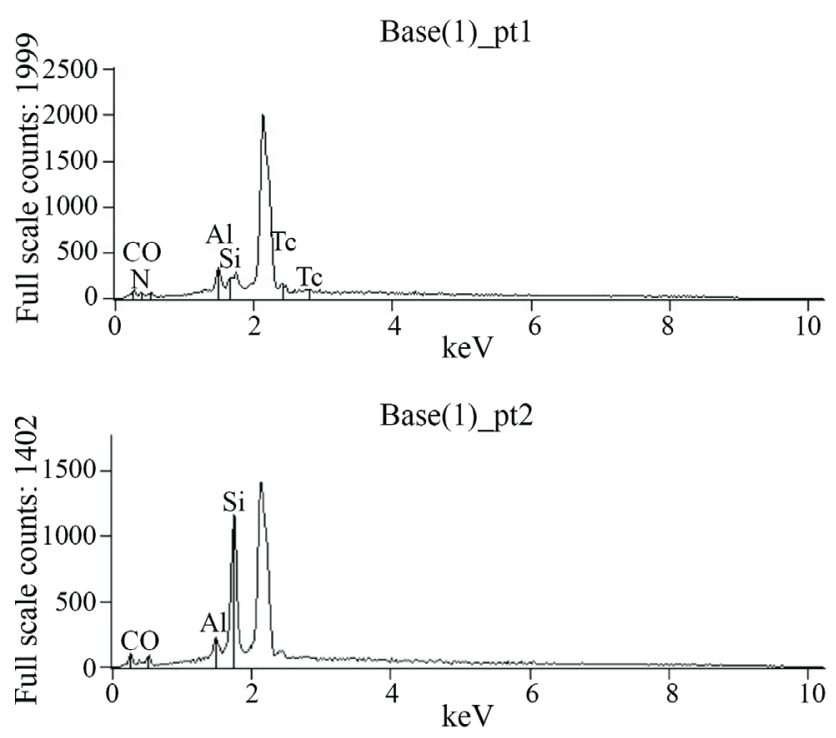

Figure 8 - Energy dispersive spectroscopy (EDS) of the film covering the sand particles. 
resulting in the oxidation of the iron in the oscillating region of the water table, forming a horizon of weak sandstone near the ground surface.

\subsection{Direct shear and permeability test}

A more detailed study conducted for the determination of resistance parameters and verification of a probable anisotropic behavior of these values was carried out in direct shear tests, performed on specimens molded with surface parallel and perpendicular to the ground surface. For these tests a common use equipment of the soil mechanics laboratory was used. The specimen is inserted into a split cell being ruptured in its medium horizontal plane. In order to obtain the shear stress, a dynamometric ring was used installed in its lower half. The vertical displacements were obtained with the use of an extensometer installed on the top of the specimen. All tests were performed in saturated conditions, with the specimens remaining submerged for $48 \mathrm{~h}$ prior to their start. The shear stage was performed at a constant velocity of $2.5 \mathrm{E}-6 \mathrm{~m} / \mathrm{s}$.

The results of the variation of the shear strength and the vertical displacement of the direct shear tests, performed in blocks 1 and 2, are shown respectively in Figs. 9and 10 . In these figures it is observed that a reduction occurs in the value of the shear strength right after reaching its maximum value. However, this reduction occurs more abruptly in sandstone samples from block 2 (Fig. 10), thus presenting a more brittle behavior. In all tests the shear strength tends to stabilize at a residual value after reaching its maximum value. The measures of height variation of the specimens during the shear stage indicate that all ruptured with larger volume than the initial one. As the normal stress of the test is increased, these volumetric variations become smaller. In the tests performed in block 1 (Fig. 9) it was observed that there are no reductions in the vertical displacement of the specimens after reaching the maximum shear strength. Vertical displacements tend to stabilize as the horizontal displacement value increases. A different behavior was observed for the test specimens of block 2 (Fig. 10). The vertical displacements increase until the rupture, followed by an abrupt reduction in value followed by an increase according as to which horizontal displacement increases. This again shows a more brittle behavior of the sandstone of block 2 . The increase in volume is related to the rolling of one grain of sand on the other along the shear plane. It can be observed during tests the sound of grain breaking.

In Table 4 are the values of the peak and residual shear strength of each of the tests presented in Figs. 9 and 10. These values are plotted in Fig. 11 depending on the normal pressure applied during the test. It can be seen in this figure that the results of the tests performed on each of the blocks, in parallel and perpendicular condition to the surface of the terrain, define the same rupture envelope. This indicates an isotropic behavior regarding the shear strength. In this way, only one rupture envelope was determined for each of the sandstone blocks and one shear envelope for the residual shear strength. These 3 rupture envelopes are plotted in Fig. 11. The strength parameters associated with the envelopes and their correlation coefficients $\left(\mathrm{R}^{2}\right)$ are shown in Table 5 .

The rupture envelope obtained for the sandstone of block 2 shows cohesion of $393.2 \mathrm{kPa}$ and angle of friction equal to $55.6^{\circ}$. These values are higher than the results found for block 1, whose cohesion is $240 \mathrm{kPa}$ and angle of friction is $47.8^{\circ}$. The residual strength values of all the tests, represented by unfilled symbols, defined a single rupture envelope with an angle of friction equal to $41.7^{\circ}$.

It is seen in Table 5 that the shear strength parameters of the sandstone of block 2 are larger and have a better correlation coefficient $\left(R^{2}=0.96\right)$. This is related to the fact that the specimens from block 2 have been molded from a region of the block which has a darker brown coloration. During field work, it was observed that this region offers a higher resistance to excavation and therefore is more resistant. The high values of the friction angle must be related to

Table 4 - Results of the direct shear tests performed on blocks 1 and 2 specimens.

\begin{tabular}{|c|c|c|c|c|c|c|c|}
\hline \multirow[t]{2}{*}{ Sample and shear direction } & \multirow{2}{*}{$\begin{array}{l}\text { Shear strength } \\
(\mathrm{kPa})\end{array}$} & \multicolumn{6}{|c|}{ Normal Pressure $(\mathrm{kPa})$} \\
\hline & & 100 & 200 & 300 & 400 & 500 & 600 \\
\hline \multirow[t]{2}{*}{ Block1 (Parallel) } & $\tau_{\text {peak }}$ & - & 478.5 & 659.5 & - & 796.5 & 903.5 \\
\hline & $\tau_{\text {residual }}$ & - & 221.3 & 247.1 & - & 424.1 & 540.1 \\
\hline \multirow[t]{2}{*}{ Block1 (Perpendicular) } & $\tau_{\text {peak }}$ & - & 385.5 & 592.4 & - & 676.8 & 951.2 \\
\hline & $\tau_{\text {residual }}$ & - & 87.4 & 251.8 & - & 381.6 & 539.2 \\
\hline \multirow[t]{2}{*}{ Block 2 (Parallel) } & $\tau_{\text {peak }}$ & 601.3 & 712.3 & - & 1039.3 & - & 1247.6 \\
\hline & $\tau_{\text {residual }}$ & 109.1 & 192.2 & - & 405.8 & - & 526.3 \\
\hline \multirow[t]{2}{*}{ Block2 (Perpendicular) } & $\tau_{\text {peak }}$ & 447.6 & 681.2 & - & 954 & - & - \\
\hline & $\tau_{\text {residual }}$ & 109.1 & 204.6 & - & 424.6 & - & - \\
\hline
\end{tabular}

$\tau_{\text {peak }}$ - peak shear strength; $\tau_{\text {residual }}-$ residual shear strength. 

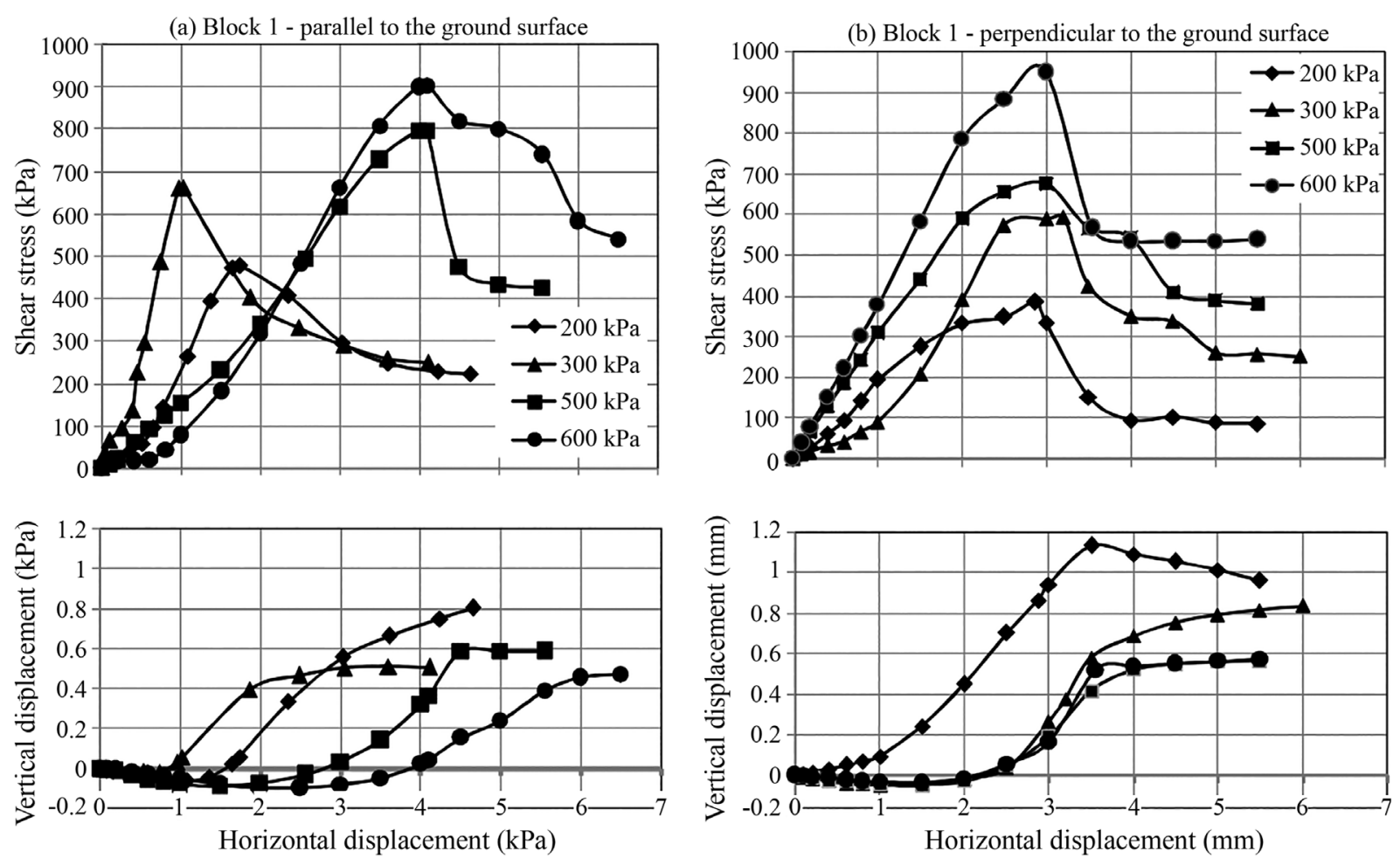

Figure 9 - Results of the direct shear tests performed on molded specimens of block 1 with a direction perpendicular and parallel to the ground surface.
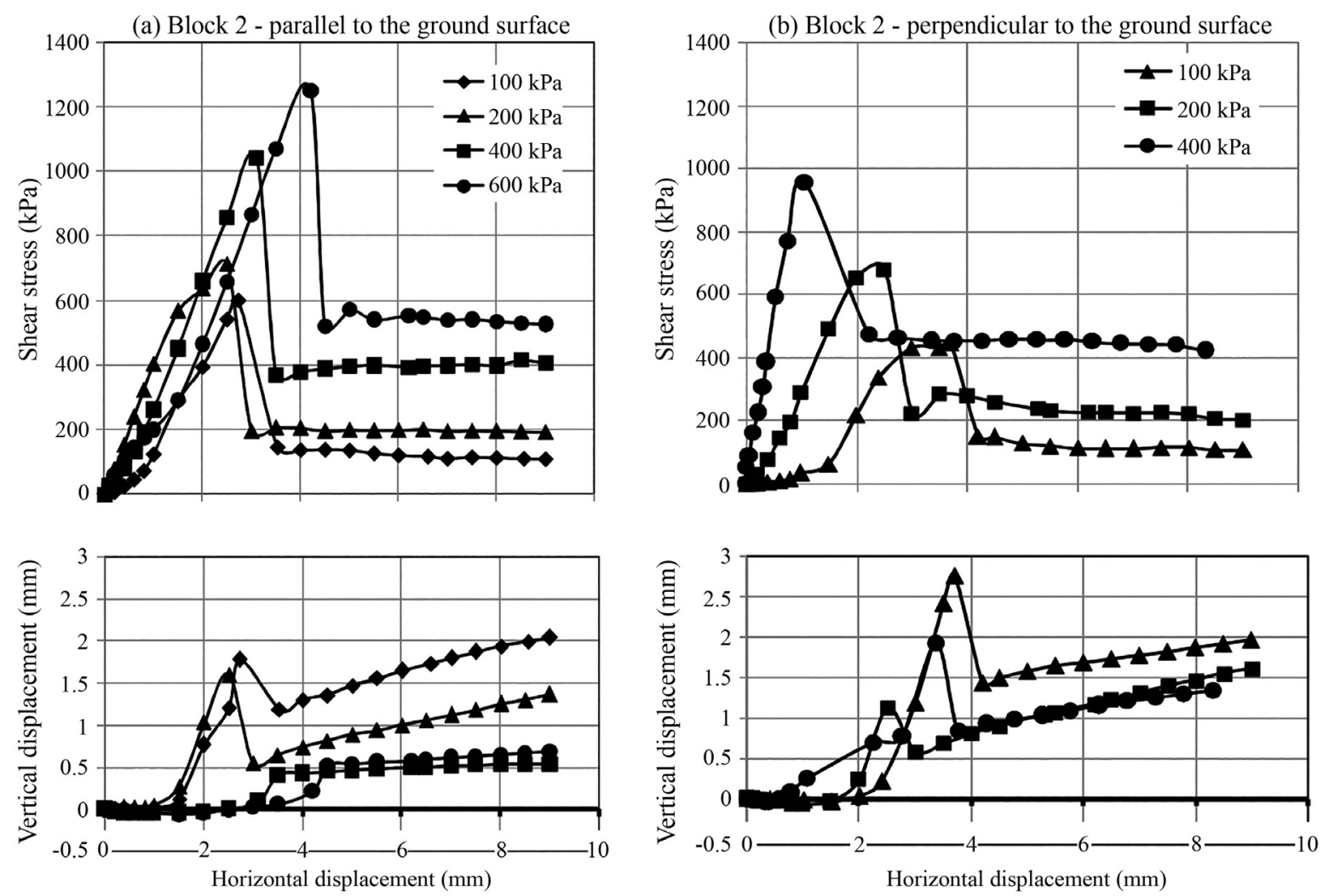

Figure 10 - Results of the direct shear tests performed on molded specimens of block 2 with a direction perpendicular and parallel to the ground surface. 


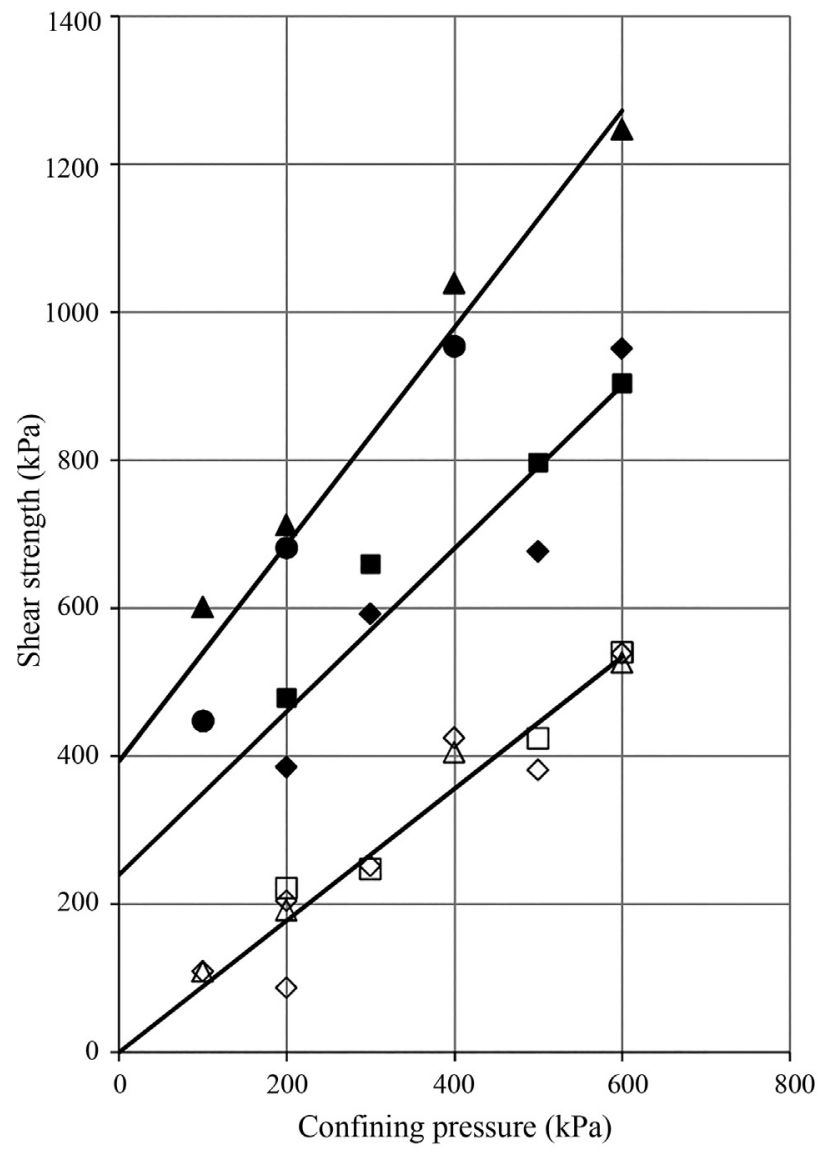

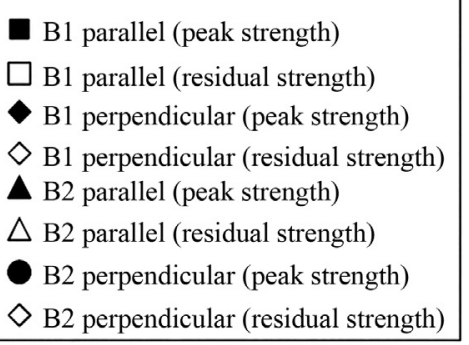

Figure 11 - Results of the direct shear tests performed in the flooded condition.

the interlocking between the sediment particles that compose the sandstone. The sandy sediments are the predominant granulometric fraction in the sandstones of blocks 1 and 2. The angular to sub-angular shape with low sphericity of these sandy particles, identified in the scanning electron microscopy, allow a good interlocking between them. Barton (1993) found, for a sand of the Grantham Formation

Table 5 - Strength parameters obtained from the direct shear tests.

\begin{tabular}{lccc}
\hline Block & c' $^{\prime}(\mathrm{kPa})$ & $\varphi^{\prime}$ & $\mathrm{R}^{2}$ \\
\hline 1 (peak) & 240.0 & $47.8^{\circ}$ & 0.89 \\
2 (peak) & 393.2 & $55.6^{\circ}$ & 0.96 \\
1 and 2 (residual) & 0 & $41.7^{\circ}$ & 0.93 \\
\hline
\end{tabular}

(United Kingdom), a friction angle of $58.4^{\circ}$, provided by the mesh between the grains. Direct shear tests perpendicular to the stratification planes, performed by Ferraz et al. (1981) in the Bauru Group sandstones, belonging to the Caiuá Formation, provided values similar to the values of the sandstones of blocks 1 and 2. The tests performed on specimens with natural moisture, showed a friction angle of $53^{\circ}$ and cohesion of $560 \mathrm{kPa}$. Fernandes (1981), studying the landslide in the Botucatu sandstone (Botucatu Formation), in the Serra da Esperança (PR), verified in direct shear test, a cohesion of $490 \mathrm{kPa}$ and friction angle of $64^{\circ}$. In the case of studies performed by Fernandes (1981), the high value of the friction angle is attributed to the low levels of normal stresses used in the tests, which should decrease to higher levels of stress. This same justification can also be applied to the sandstones of blocks 1 and 2 as a second factor related to the high friction angle found. The maximum normal stress applied in the direct shear tests performed in the sandstones of blocks 1 and 2 was $600 \mathrm{kPa}$, which is a low value, however, representative of the tensions transmitted by building foundations. The values of the friction angle should decrease with the increase of the normal stress due to non-linearity of the rupture envelopes.

To verify the hydraulic conductivity of these sandstones, permeability tests were performed using the TRIFLEX 2 equipment manufactured by Soil Moisture. Using two specimens of block 1, molded with a diameter and height of $10 \mathrm{~cm}$, tests were performed in the direction parallel and perpendicular to the ground surface. For these tests the specimens were saturated by backpressure. Inside the test cell the specimen was wrapped in a rubber membrane and subjected to a confining pressure of $230 \mathrm{kPa}$. For saturation was applied at its top a pressure of $220 \mathrm{kPa}$ and at its base a pressure of $200 \mathrm{kPa}$, remaining under this hydraulic gradient for a period of $48 \mathrm{~h}$. Due to the limited number of samples, this test could not be performed on the sandstone of block 2 .

In the parallel and perpendicular direction, the permeability values were respectively $4.8 \mathrm{E}-6$ and $5.6 \mathrm{E}-6 \mathrm{~m} / \mathrm{s}$. These values are within the range of variation obtained by Dobereiner and Freitas (1996) when testing soft sandstones of Portugal, England, Brazil and Turkey. In their experiments they obtained values of permeability ranging from $1.8 \mathrm{E}-5 \mathrm{~m} / \mathrm{s}$ to $8.9 \mathrm{E}-6 \mathrm{~m} / \mathrm{s}$. The results of direct shear tests and permeability tests indicate that Pleistocene sandstones exhibit isotropic behavior in relation to their mechanical and hydraulic properties.

\subsection{Unconfined compressive strength test}

The equipment used in soil mechanics is inadequate for the molding of specimens of this sandstone. The weak sandstone was first sawed in a prismatic shape with a square base. The refining, leaving the specimens of $4 \mathrm{~cm}$ in diameter and $8 \mathrm{~cm}$ in height, was given by a scraping process using a molding lathe. The specimens from block 1 
were allowed to air dry. In this condition, the values of the degree of saturation varied between 20.4 and $27.2 \%$. In order to verify the influence of the moisture content on the resistance values, the molded specimens of block 2 were submerged for a period of 3 days. In this procedure the samples were initially submerged in water up to $1 / 3$ of their height, remaining there for a period of two hours. After this initial stage the water level was raised to $2 / 3$ of its heights, remaining in this condition for the same time interval. In the final stage they remained submerged until completing a period of 3 days. The purpose of this procedure is to saturate the sample by capillarity. After the period of 3 days, the values of the degree of saturation varied between $60.7 \%$ and $68.3 \%$. These values were lower than expected. This fact is probably associated with the presence of hydrophobic organic compounds (Mataix-Solera et al., 2007; Wallach et al., 2005; Dekker et al., 1998). The presence of organic material in the sandstones of blocks 1 and 2 was verified in the analysis of scanning electron microscopy and method of burning.

The unconfined compressive strength tests were performed with a strain rate of $0.1 \mathrm{~mm} / \mathrm{min}$, adopting the recommendations established in standard D 2938-71 (ASTM). For these tests a press was used in the laboratory of soil mechanics. To obtain the values of the normal stress applied at the top of the specimen during the test a dynamometric ring was used. To avoid loss of moisture, the specimens were sealed in plastic film. Due to the difficulties to glue strain gauges to the surface of the weak rocks (Almisned et al., 2011; Chen \& Hu, 2003), the axial strains were obtained by using an extensometer placed on top of the compression cell. The values of the physical indices of the specimens and the results of the unconfined shear tests are presented in Tables 6 and 7. The variations of the stress as a function of the axial deformations are presented in Fig. 12.

Comparing Tables 6 and 7, it can be seen that the mean values of the unconfined shear strength of the specimens of blocks 1 and 2 are similar. However, the mean value of the modulus of deformability of the test specimens of block 1 is $33 \%$ greater than the value found for the tests of block 2. The values of the unconfined compressive strength tests and the modulus of deformability are shown in Figs. 13 and 14 as a function of the water moisture content. In Fig. 13 it is observed that the values of the unconfined compressive strength tests of block 1 have a greater dispersion when compared to the values of block 2. This same conclusion is also valid for the values of the tangent deformability modules presented in Fig. 14. However, it is observed that the results of block 2, presented in Figs. 13 and 14, vary within the range of the results of the tests performed in the sandstone of block 1 . The greater dispersion of the results of block 1 is probably related to the fact that it is located in a transition region between the sandy sediments and the sandstone (Fig. 5).

In the results of direct shear tests, presented in Table 5, it was also observed a greater dispersion in the results

Table 6 - Results of the unconfined compressive strength tests of Block 1.

\begin{tabular}{|c|c|c|c|c|c|c|}
\hline Specimens & $\gamma_{d}\left(\mathrm{kN} / \mathrm{m}^{3}\right)$ & $\mathrm{w}(\%)$ & $\mathrm{S}(\%)$ & $\mathrm{n}(\%)$ & $\sigma_{c}(\mathrm{MPa})$ & $E_{t g}(\mathrm{MPa})$ \\
\hline 1B1 & 17.10 & 4.08 & 20.40 & 34.20 & 2.06 & 157.00 \\
\hline $2 \mathrm{~B} 1$ & 16.70 & 3.76 & 17.60 & 35.90 & 2.69 & 265.80 \\
\hline $3 \mathrm{~B} 1$ & 17.40 & 4.21 & 22.30 & 32.90 & 1.93 & 263.40 \\
\hline 4B1 & 16.50 & 5.31 & 24.20 & 36.30 & 2.58 & 190.60 \\
\hline $5 \mathrm{~B} 1$ & 16.80 & 5.76 & 27.20 & 35.50 & 1.44 & 74.30 \\
\hline Average value & 16.90 & 4.62 & 22.34 & 34.96 & 2.10 & 190.22 \\
\hline
\end{tabular}

$\gamma_{d}$ - specific dry weight; $\mathrm{w}_{\text {nat }}$ - water moisture content; $\mathrm{S}$ - degree of saturation; $\mathrm{n}$ - porosity; $\sigma_{c}$ - Unconfined compressive strength; $E_{t g}$ tangent deformability modulus.

Table 7 - Results of the unconfined compressive strength tests of Block 2.

\begin{tabular}{|c|c|c|c|c|c|c|}
\hline Specimens & $\gamma_{d}\left(\mathrm{kN} / \mathrm{m}^{3}\right)$ & $\mathrm{w}(\%)$ & $\mathrm{S}(\%)$ & $\mathrm{n}(\%)$ & $\sigma_{c}(\mathrm{MPa})$ & $E_{t g}(\mathrm{MPa})$ \\
\hline 1B2 & 16.90 & 14.05 & 68.30 & 34.60 & 2.04 & 116.80 \\
\hline $2 \mathrm{~B} 2$ & 17.20 & 12.86 & 65.40 & 33.80 & 2.36 & 136.60 \\
\hline $3 \mathrm{~B} 2$ & 16.60 & 14.20 & 65.40 & 35.90 & 1.66 & 136.70 \\
\hline $4 \mathrm{~B} 2$ & 16.60 & 13.25 & 60.70 & 36.30 & 1.48 & 115.20 \\
\hline Average value & 16.83 & 13.59 & 64.95 & 35.15 & 1.90 & 126.33 \\
\hline
\end{tabular}

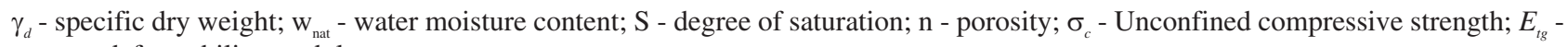
tangent deformability modulus. 


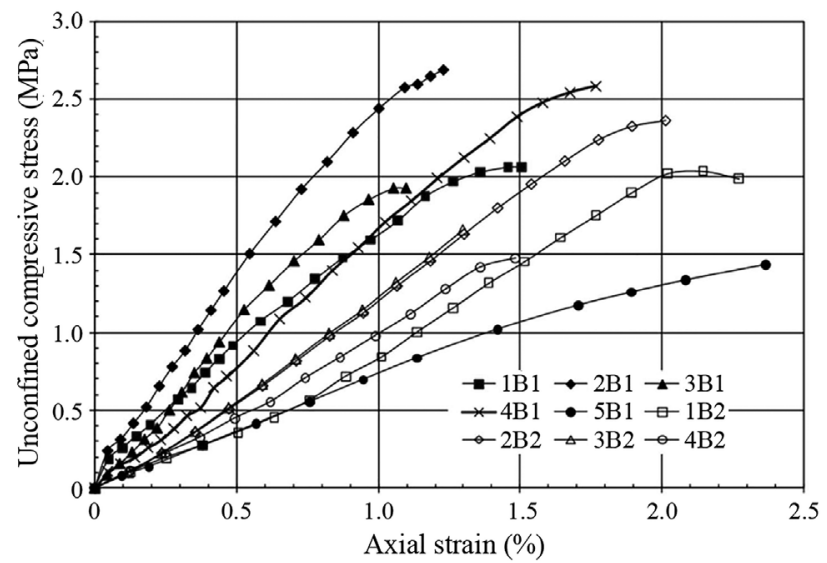

Figure 12 - Stress-strain curve of the unconfined compressive strength tests performed on the weak sandstone of blocks 1 and 2 .

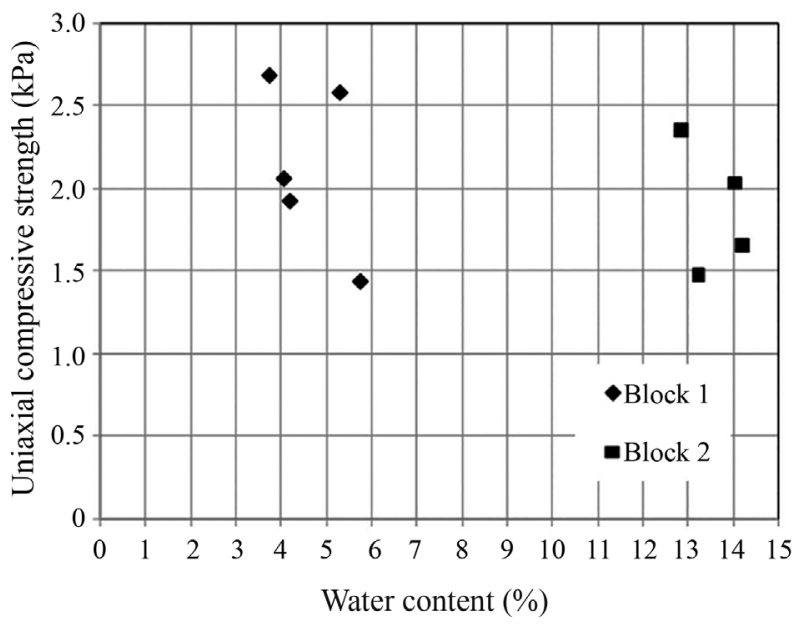

Figure 13 - Relation between the unconfined compressive strength tests and water moisture content.

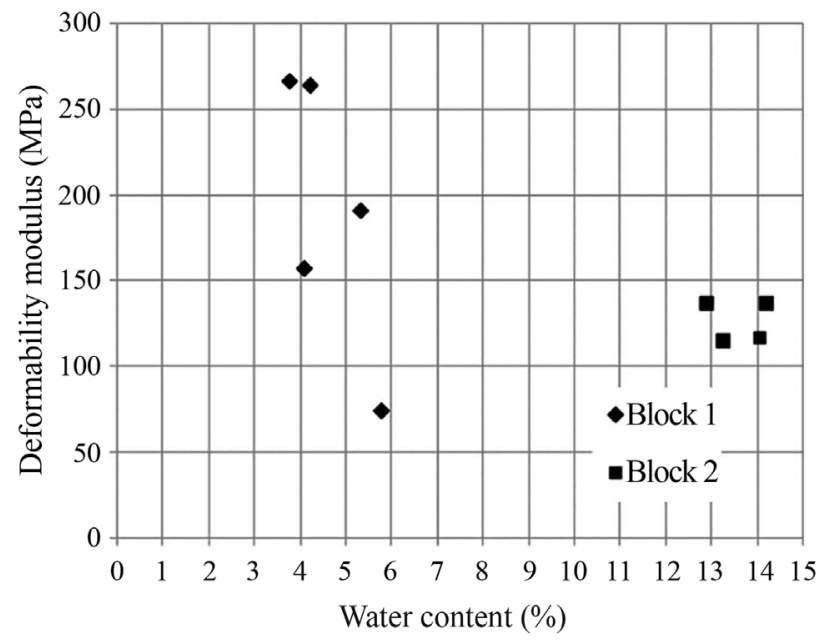

Figure 14 - Relation between the tangent deformability modulus and water moisture content of the unconfined compressive strength tests. obtained from block 1. However, in the unconfined compressive strength tests a new variable was introduced. The specimens from block 1 were tested with a lower moisture content than the specimens from block 2 . This difference in moisture content had a considerable influence on the results of simple compression tests. Comparing the results of Tables 6 and 7, it can be observed that a reduction in the moisture content causes an increase in the value of the unconfined compressive strength and deformability modulus. Dobereiner \& Dyke (1986) also obtained the same type of result when testing three types of sandstone with different moisture contents.

Armaghani et al. (2016) and Kim et al. (2017) present several correlations between simple compression strength and some sandstone properties, including the Schmidt hammer rebound number, point load test and wave velocity.

The mechanical and hydraulic properties of the weak rocks determined in laboratory tests are important because they represent values of the rock mass (Oliveira, 1993). Due to the plasticity of the weak rocks, which do not allow relevant fractures, it is almost always possible to consider the deformability of the rock mass as approximately equal to that obtained in laboratory tests (Rocha, 1975). Therefore, for the purpose of classification, the average values of unconfined shear test results presented in Tables 6 and 7 will be considered as representative parameter of the sandstone rock mass.

The values of the unconfined compressive strength, presented in the Tables 6 e 7, varied between 1.5 and 2.7 MPa, with an average value of $2 \mathrm{MPa}$, and the values of the modulus of deformability varied between 115 and $266 \mathrm{MPa}$, with an average value of $162 \mathrm{MPa}$. These ranges of unconfined compressive strength values and deformability modulus are compatible with porous rocks, such as sandstones that have heterogeneous mechanical behavior evidenced by dispersion in the values of their mechanical properties (Gama, 1994).

In Fig. 15, some proposals for the classification of rocks that use the value of unconfined shear strength are presented. Using the average value of $2 \mathrm{MPa}$ as representative of the sandstones studied here, it is observed that this rock is classified as a weak rock according to the proposal of the Geological Society of London (1970) and as very weak by the ISRM (1978) and Dobereiner (1984).

Figure 16 shows the relationship between the modulus of deformability and the resistance to simple compression, obtained by Dobereiner (1984), when investigating 11 different types of weak sandstones. Point 12 indicated in this figure corresponds to the results obtained for the soft sandstones of this research, represented by the uniaxial compressive strength of $2 \mathrm{MPa}$ and tangential deformability modulus of $162 \mathrm{MPa}$. It can be seen in Fig. 16 that point 12 shows a good correlation with the results obtained by Dobereiner (1984). 


\section{Use of Sandstone as a Foundation Material}

In the region located $300 \mathrm{~m}$ from the site of removal of the two blocks of sandstones, a concrete building with 16 floors was built. The Fig. 17 photo illustrates the excavation for execution of the shallow foundation. It can be observed in this figure that the soil profile is formed by sandy sediments followed by abrupt transition to weak sandstone. The structural system of this building has reduced rigidity due to the distances between the pillars.

The terrain is inserted in the Pleistocene marine terrace, being its geological profile presented in Fig. 18a. The shallow foundations were designed to be built directly on the sandstone (depth of $3.8 \mathrm{~m}$ ), and the value of $100 \mathrm{MPa}$ was adopted for its tangential deformability modulus. The pillars were instrumented and the displacement monitored from the beginning of the construction, for 16 months. The maximum settlement was of the order of $30 \mathrm{~mm}$. The representative curves of the same settlement value (Fig. 18b) indicate that the building presented a small slope of $1 / 2250$ to the east. The parallelism of these curves indicates that the

Uniaxial Compressive Strength (MPa)

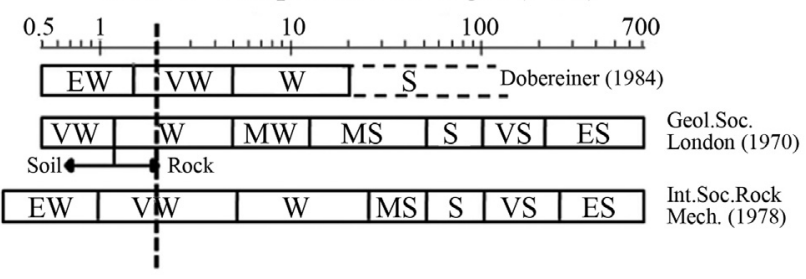

Figure 15 - Proposals for classification of rocks as a function of unconfined shear strength modified from Dobereiner \& Freitas (1986) (EW, extremely weak; VW, very weak; W, weak; MW, moderately weak; MS, moderately strong; S, strong; VS, very strong; ES, extremely strong). weak sandstone worked as a rigid plate reducing the differential settlement. The performance of the shallow founda-

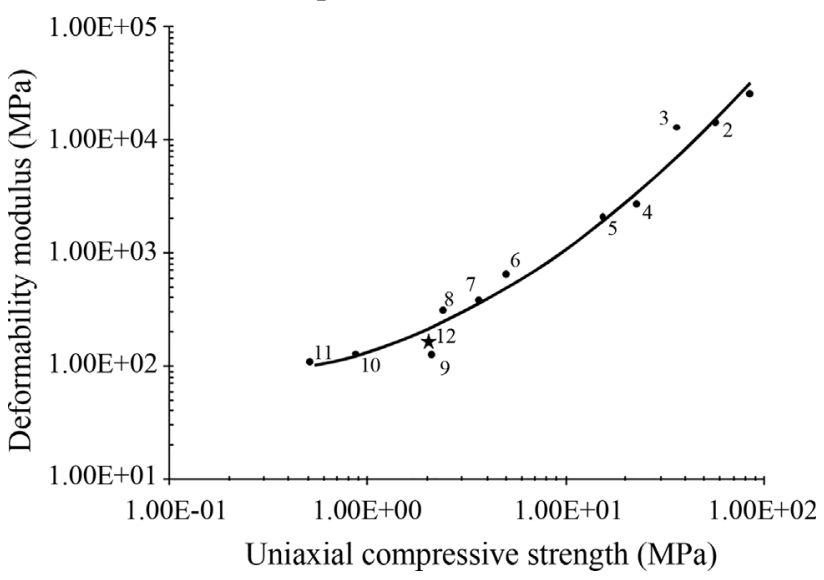

Figure 16 - Correlation between the tangential deformability modulus and the unconfined shear strength obtained by Dobereiner, 1984

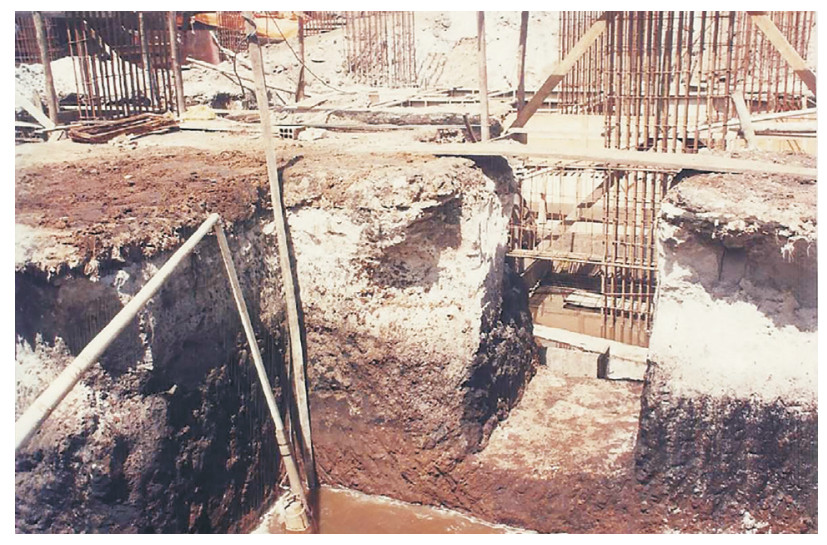

Figure 17 - Excavation for the execution of a superficial foundation on the sandstone.

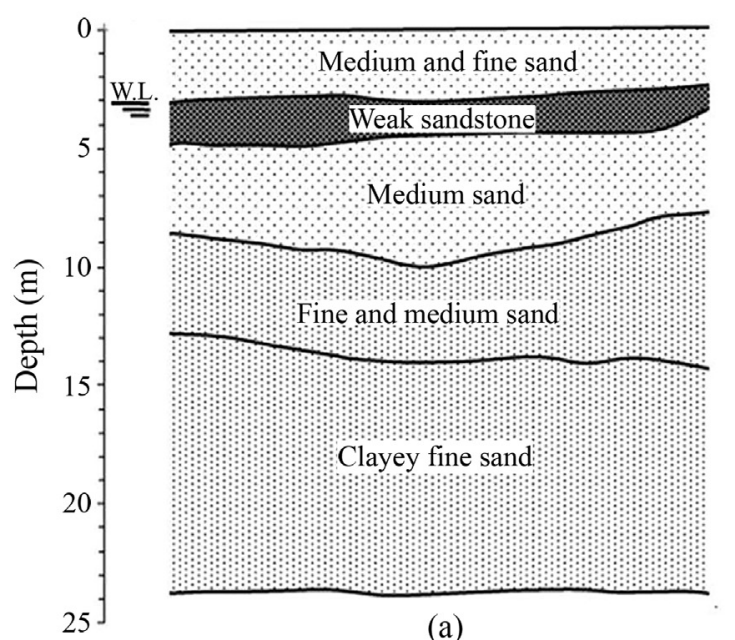

(a)

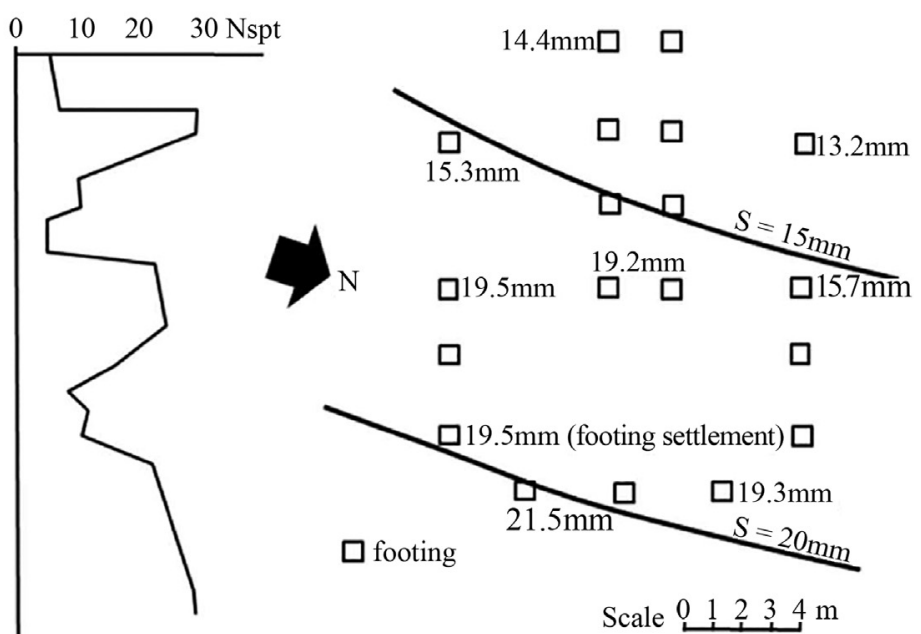

(b)

Figure 18 - (a) Geotechnical profile of the ground where a superficial foundation was executed on the sandstone. (b) Curves of the same displacement (Gusmão Filho, 1998). 
tions built directly on these sandstones has been excellent, allowing for more economical solutions (Gusmão Filho, 1998).

\section{Conclusions}

The sandy sediments of the Pleistocene Marine Terrace, located in the Metropolitan Region of the City of Recife/Brazil, were submitted to diagenetic processes that resulted in the formation of a layer of sandstone, cemented by humic acid. Analyzing the boring database, used in the elaboration of the Geotechnical Chart of the City of Recife, it was found that these sandstones are located near the ground surface forming a horizontal slab with thicknesses ranging from 0.5 to $4.5 \mathrm{~m}$, being present at a depth of 0.3 to $4.5 \mathrm{~m}$. Based on the classifications proposed by ISRM (1978) and by Dobereiner (1984), these sandstones are classified as very weak rock with mean values of unconfined compressive strength and modulus of deformability, respectively, equal to $2 \mathrm{MPa}$ and $162 \mathrm{MPa}$. The results of the hydraulic conductivity and direct shear tests conducted in the direction parallel and perpendicular to the ground surface indicate that these sandstones present as isotropic material. This rock formation is present in a large part of the coastal region of Brazil and its good performance, observed in a case study, indicates that this material may be suitable as support to shallow foundations of buildings.

\section{References}

ABNT (1996). Brazilian Association of Technical Standards. NBR 13600: Determination of Organic Material Content by Igniting at $400{ }^{\circ} \mathrm{C}$ - Method of Test. Rio de Janeiro, 2 p. (in portuguese)

ABNT (2001). Brazilian Association of Technical Standards. NBR 6484: Soil - Standard Penetration Test SPT - Soil Sampling and Classification: Test Method. Rio de Janeiro, 17 p. (in portuguese)

ABNT (2016a). Brazilian Association of Technical Standards. NBR 6457: Soil Samples - Preparation for Compactation and Characterization Tests. Rio de Janeiro, 9 p. (in portuguese)

ABNT (2016b). Brazilian Association of Technical Standards. NBR 6458: Gravel Grains Retained on the 4.8 mm Mesh Sieve: Determination of the Specific Gravity, of the Apparent Specific Gravity and of Water Absorption. Rio de Janeiro, 6 p. (in portuguese)

ABNT (2016c). Brazilian Association of Technical Standards. NBR 7181: Grain Size Analyses. Rio de Janeiro, $13 \mathrm{p}$. (in portuguese)

Almisned, O.A., Somerville, J. \& Smart, B.G.D. (2011). Difficulties in Laboratory Characterization of Weak Sandstone. Proc. 45th US Rock Mechanics/Geomechanics Symposium, San Francisco, United States, pp. 1-4.

Andrade, A.C.S. \& Dominguez, J.M.L. (2002). Geological-geomorphological information as subsidies to the environmental analysis: the example of the marine terrace of Caravelas-Bahia. Bulletin Paranaense de Geosciences, 51:9-17.

Armaghani, D.J., Amim M. F.M., Yagiz, S., Faradonbeh, R.S. \& Abdullah, R.A. (2016). Prediction of the uniaxial compressive strength of sandstone using various modeling techniques. International Journal of Rock Mechanics \& Mining Sciences, 85(5):174-186.

Assis, H.M.B. (1990). Beach Rocks Studies of the South Coast of Pernambuco Based on Petrographic and Isotopic Evidence, MSc. Dissertation, Federal University of Pernambuco, Recife (PE), 91 p. (in portuguese)

ASTM (1971). Standard Test Method for Unconfined Compressive Strength of Intact Rock Core Specimens D2938. ASTM International, West Conshohocken, Pennsylvania, USA, 4 p.

Barton, M.E. (1993). Cohesive sands: The natural transition from sands to sandstones. Proc. Geotechnical Engineering of Hard Soils-Soft Rocks. Anagnostopoulose et al. (eds), Balkama, Rotterdam, pp. 367-374.

Baver, L.D. (1968). The effect of organic matter on soil structure. In: Study Week on Organic Matter and Soil Fertility. John Wiley \& Sons, New York. pp. 383-413.

Bigarella, J.J.; Becker, R.D. \& Passos, E. (2007). Structure and Origin of Tropical and Sutropical Landscapes. Vol. 2. 2nd Edition. Publisher of UFSC. 875 p. (in portuguese)

Chen, H. \& Hu, Z. (2003). Some factors affecting the uniaxial strength of weak sandstones. Bull. Eng. Geol. Env., 62(4):323-332.

Dekker, L.W.; Ritsema, C.J.; Oostindie, K.; Ziogas, A.K. \& Boersma, O.H. (1998). Effect of drying temperature on the severity of soil water repellency. Soil Science, 163(10):780-796.

Dobereiner, L. \& Dyke, C. (1986). Characteristics of the deformability of sandstones in function of the variation of the moisture content. Proc. 2th South American Symposium on Rock Mechanics, Porto Alegre / RS, pp. 5765. (in portuguese)

Dobereiner, L. (1984). Engineering Geology of Weak Sandstones. PhD Dissertation, Department of Geology, Imperial College, $471 \mathrm{p}$.

Dobereiner, L. \& Freitas, M.H. (1986). Geotechnical properties of weak sandstones. Geotechnique, 36(1):79-94.

Ferraz, J.L.; Minicucci, L.A. \& Armelin, J. A. (1981). Preliminary geotechnical characterization of caiuá sandstone occurring at Pontal do Paranapanema. Proc. 3th Brazilian Congress on Engineering Geology, Itape$\mathrm{ma} / \mathrm{SP}$, v.3, pp 55-88. (in portuguese)

Fernandes, C.E.M. (1981). Geological-geotechnical studies for the stabilization of cutting slopes in BR-277 Serra da Esperança (PR). Proc. 3th Brazilian Congress on Engineering Geology, Itapema/SP, v.3, pp 33-54. (in portuguese) 
Gama, E.M. (1994). High technology in mechanical testing laboratory with rocks. Journal Soils and Rocks, 17(2):131-143.

Geological Society of London (1970). The logging of rock cores for engineering purposes. Quarterly Journal of Engineering Geology and Hydrogeology, 3(1):1-24.

Gusmão Filho, J.A. (1998). Foundations: from Geological Knowledge to Engineering Practice. Recife: University Publishing House- Federal University of Pernambuco/UFPE, 345p. (in portuguese)

ISRM (1978). Suggested methods for the quantitative descriptions of discontinuities in rock masses. Int. J. Rock. Min. Sci., 15(6):319-368.

Kanji, M.A. (2014). Critical issues in soft rocks. Journal of Rock Mechanics and Geotechnical Engineering, 6(3):186-195.

Kim, E.; Stine, M.A.; Oliveira, D.B.M. \& Changani, H. (2017). Correlations between the physical and mechanical properties of sandstones with changes of water content and loading rates. International Journal of Rock Mechanics \& Mining Sciences, 100:255-262.

Mabessone, J.M. (1967). Sedimentology of the coastline between Recife-João Pessoa, Bulletin of the Brazilian Society of Geology, 16(1):57-72.

Manso, V.A.V.; Motta, J.A.; Guerra, N. C. \& Soares Júnior, C.F.A. (2003). Final Report - Definition of the contour points of the maximum tidal line of the coast of the municipality of Ipojuca / PE. Reference term MMA / PNMA II - SECTMA No 249. (in portuguese)

Mataix-Solera, J.; Arcenegui, V.; Guerrero, C.; Mayoral, A.M..; Morales, J.; González, J.; García-Orenes, F. \& Gómez; I. (2007). Water repellency under different plant species in a calcareous forest soil in a semi arid Mediterranean environment. Hydrological Processes, Bristol, 21(17):2300-2309.
Oliveira, R. (1993). Weak rock materials. Proc. 26th Annual Conference of the Engineering Group of the Geological Society. United Kingdom. A.A. Balkema, pp. 5-15.

Rocha M. (1975). Some problems related to the rock mechanics of low strength natural materials. Proc. 5th Pan-American Conference on Soil Mechanics and Foundation Engineering, Buenos Aires; pp. 489-514. (in portuguese)

Suguio, K.; Martin, L.; Bittencourt, A.C.S.P.; Dominguez, J.M.L.; Flexor, J.M. \& Azevedo, A.E.G. (1985). Relative sea level Fluctuations During the quaternary period along the brazilian coast and its implications on coastal sedimentation. Brazilian Journal of Geosciences, 15(4):273-286.

Tisdall, J.M. \& Oades, J.M. (1982). Organic matter and water-stable aggregates in soil. J. Soil Sci., 33:141-163.

Wallach, R.; Ben-Arie O. \& Graber E.R. (2005). Soil water repellency induced by long-term irrigation with treated sewage effluent. J. Environ. Qual., 34(5):1910-1920.

\section{List of Symbols}

$c^{\prime}$ : cohesion intercept

$E_{t}:$ tangent deformability modulus

$\varphi^{\prime}$ : friction angle

$\varphi^{\prime}{ }_{\text {resid. }}$ : residual friction angle

$\gamma_{d}:$ specific dry weight

$\gamma_{s}$ : density of solid particles

$\mathrm{n}$ : porosity

QH: quaternary Holocene Unit

QP: quaternary Pleistocene Unit

QU: quaternary Undifferentiated Unit

S: degree of saturation

$\sigma_{c}$ : unconfined compressive shear strength

$\tau_{\text {peak }}:$ peak shear strength

$\tau_{\text {residual }}:$ residual shear strength

w: water moisture content

$\mathrm{w}_{\text {nat. }}$ : natural water moisture content 